\title{
The effect of ketamine on shivering in patients undergoing spinal anesthesia
}

\author{
H. kaiialha' ${ }^{1}$ A. karbord ${ }^{2}$, Sh. Rastak ${ }^{3}$, H. Mehdipor ${ }^{3}$, S. Yaaghobi ${ }^{1}$, AR. Kheshti ${ }^{4}$
}

\author{
${ }^{1} \mathrm{Bu}$-Ali Hospital, Qazvin University of Medical Science, Qazvin, Iran \\ ${ }^{2}$ Social Determinants of Health Research Center, Qazvin University of Medical Science, Qazvin, Iran \\ ${ }^{3}$ Faculty of Paramedics, Qazvin University of Medical Science, Qazvin, Iran \\ ${ }^{4}$ Department of Anesthetics, Imam Hossein Hospital, Tehran, Iran \\ Corresponding Address: Asghar Karbord, Social Determinants of Health Research Center, Qazvin University of Medical \\ Science, Qazvin, Iran \\ Tel: +98-912-2893826, Email: karbord2003@yahoo.com \\ Received: 10 Apr 2017; Accepted: 5 Aug 2017
}

\section{* Abstract}

Background: Sever shivering is the most common adverse effect of spinal anesthesia during and after operation that causes physiologic complication. One of the drugs that could decrease operative shivering is ketamine.

Objective: The aim of this study is the effect of ketamine to reduce shivering, during spinal anesthesia.

Methods: This prospective randomized, and double-blind clinical trial was conducted on 355 patients of candida different surgeries with spinal anesthesia in Bu-Ali and Velayat Hospitals in Qazvin (2017). Patients were randomly divided into experimental ( $\mathrm{n}=175)$ and control $(\mathrm{n}=180)$ groups. For the experimental and control groups, ketamine $(0.2 \mathrm{ml} / \mathrm{kg})$ or an equal volume of distilled water were administered with intravenous infusion pumps immediately after initiating spinal anesthesia, respectively. Then degree of shivering checked by anesthesiologist with visual scale during surgery.

Findings: The rate and intensity of shivering at ketamine group significantly decreased compared to the control group. Shivering during surgery was less than in men, urological surgery and age (20-40 years) in both groups.

Conclusion: Adding ketamine to drug's pump in patients undergoing spinal anesthesia could be effective method to control shivering during operation.

Keywords: Operative shivering, Spinal anesthesia, Ketamine, Intensity of shivering

Citation: Kaiialha H, Karbord A, Rastak SH, Mehdipor H, Yaaghobi C, Kheshti A. The effect of ketamine on shivering in patients undergoing spinal anesthesia. J Qazvin Univ Med Sci 2018; 21 (6): $14-21$. 


\title{
بررسى تأثير كتامين وريدى بر ميزان لرز بيماران تحت بىحسى اسبينال
}

\author{
دكتر حميد كيالها'، اصغر كاربرد'، شهرام رستاك"، حبيباله مهدى يور '، دكتر سيامك يعقبى'، دكتر عليرضا ميرخشتى
}

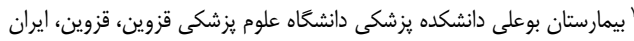

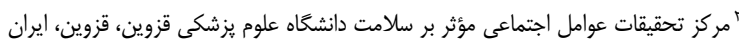

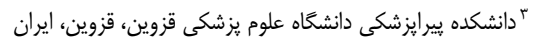

|

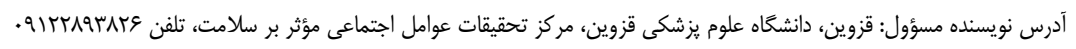

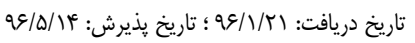

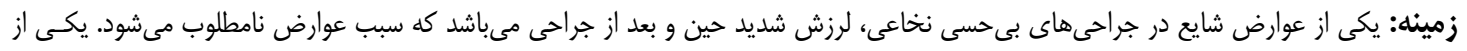

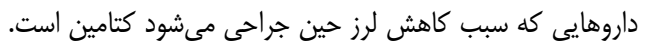

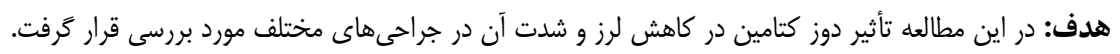

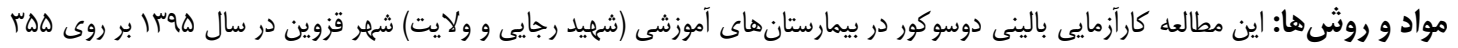

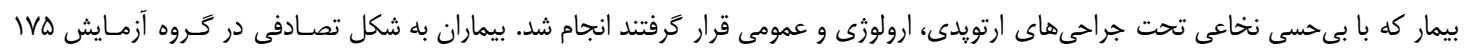

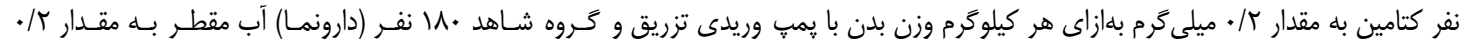

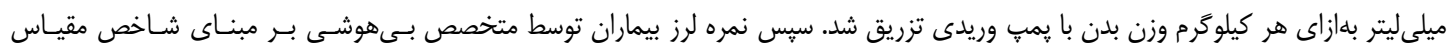
ديدارى در حين جراحى تعيين كرديد.

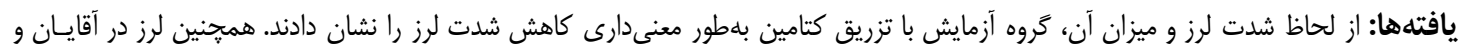

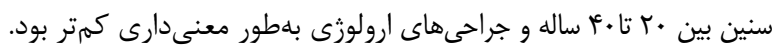

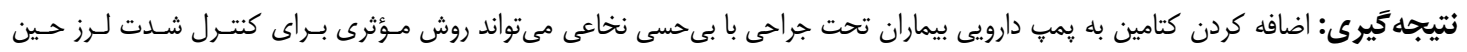
جراحى باشد. كليدوازهها: لرز حين جراحى، بى حسى نخاعى، كتامين، لرزش

\section{مقدمه:}

ميزان اكسيثن شريانى، اسيدوز متابوليـك، افـزايش فشـار

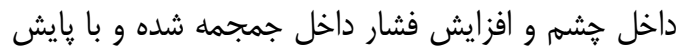

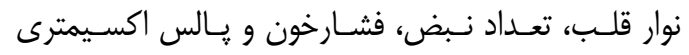
تداخل مىنمايد. (اوت")

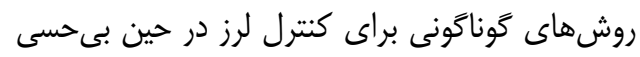

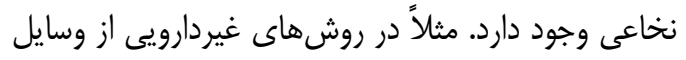

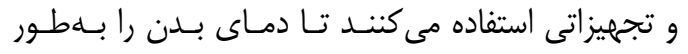
محسوسى حفظ نمايند ولى ممكـن اسـت يُرهزينـهـ و در
با توجه به اين كه بى حسى نخاعى يك روش مطمـئن

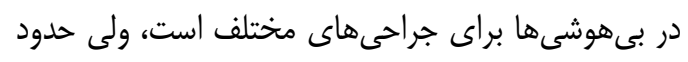

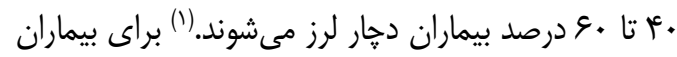

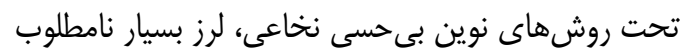

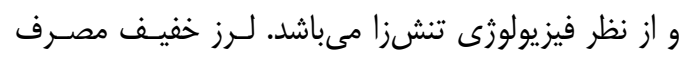

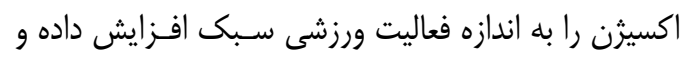

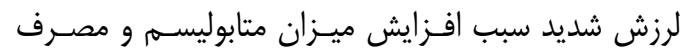

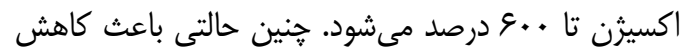




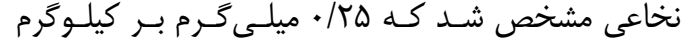

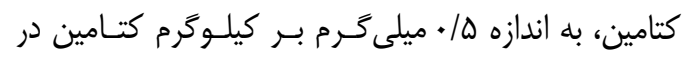

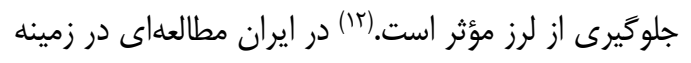

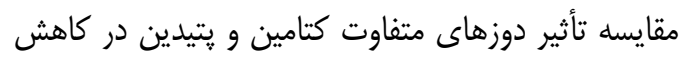

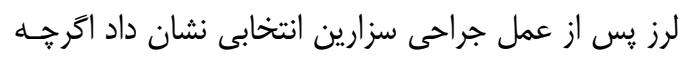

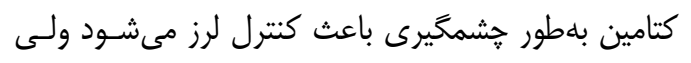

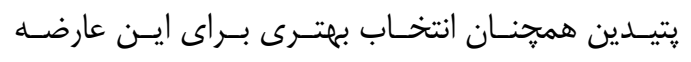

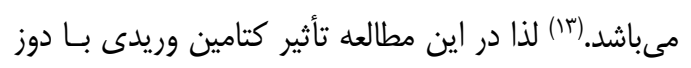

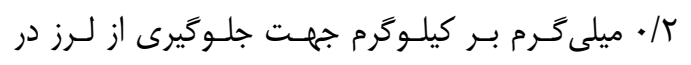
بيمارانى كه تحت بى حسى نخايى بودند، بررسى شد.

\section{جواد مواد روشها:}

جامعه آمارى اين مطالعه مداخلهاى تصادفى دوسوكور

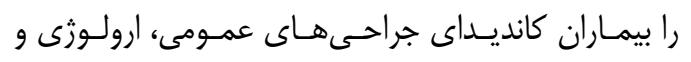

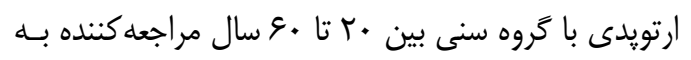

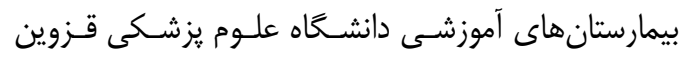

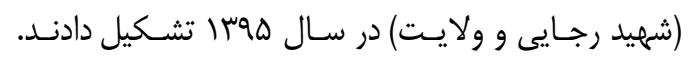

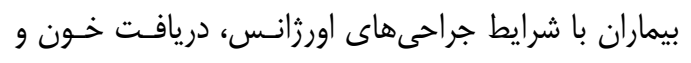

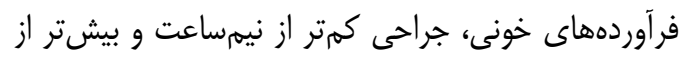
دو ساعت، بيشتر شدن طول جراحى از مدت بـ حسى كه كه

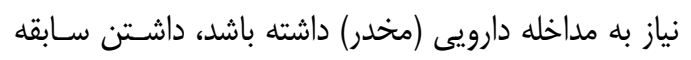

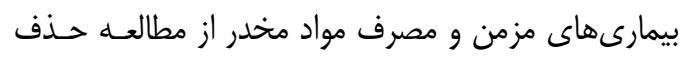

شدند.

بعد از اخذ مجوز از كميته اخلاق دانشخاه، بيمـاران بـا

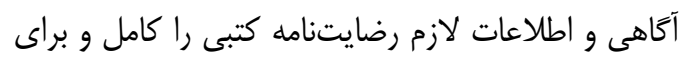

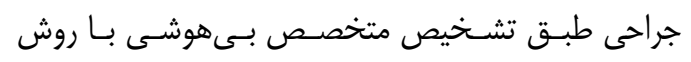

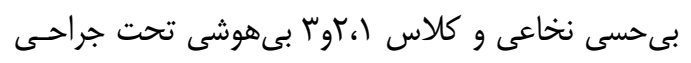

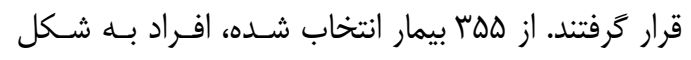

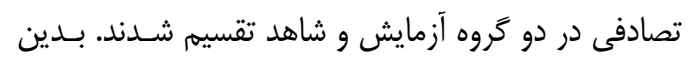

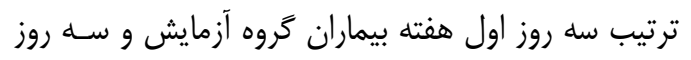

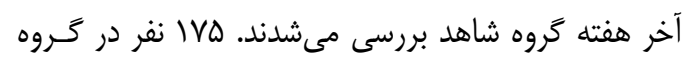

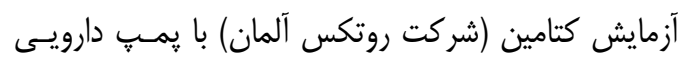

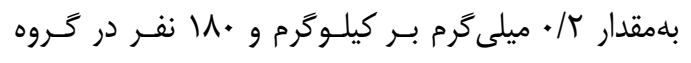

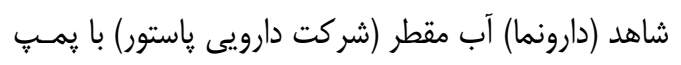

همه شرايط عملى نباشد. در روشهاى دارويى، داروهـاى مختلفى براى ييشخيرى يا درمان لرز مـورد مطالعـه قـرار

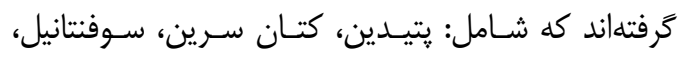

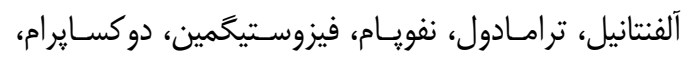

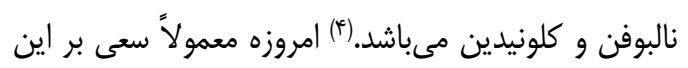

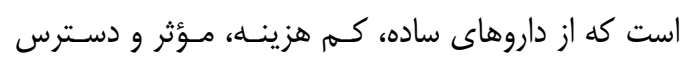

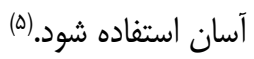

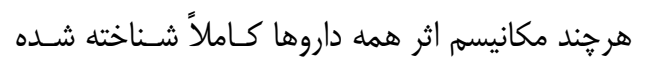

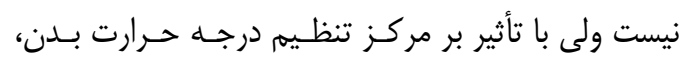

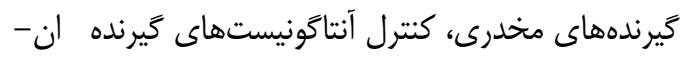

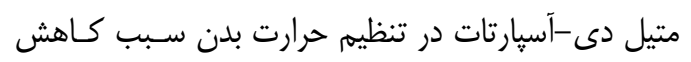

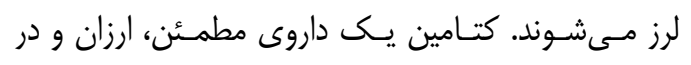

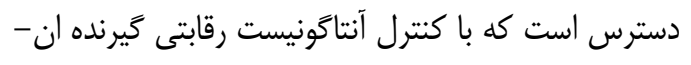

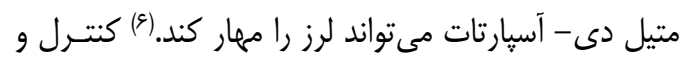

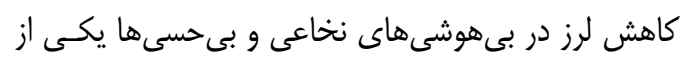

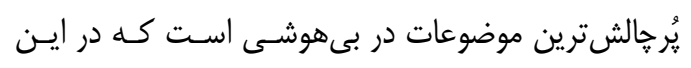
ميان داروهاى مخدر و همجنين دارويى جون كتامين تأثير

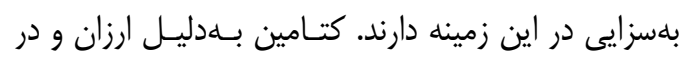
دسترس بودنش نسبت به داروهاى مخـــر در ايـن زمينـــ

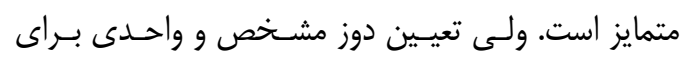

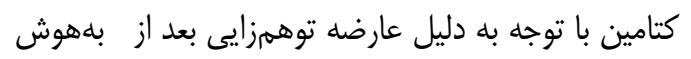

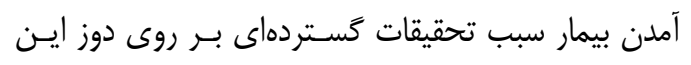

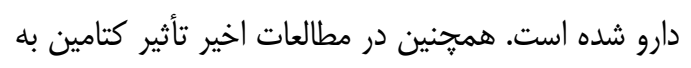

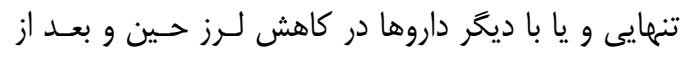

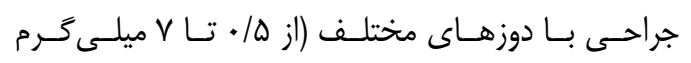

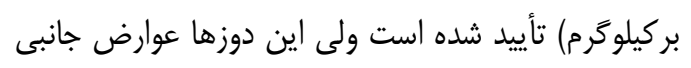

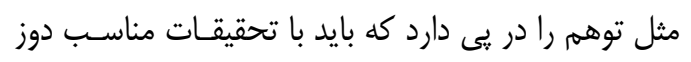

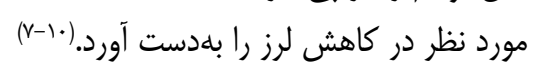

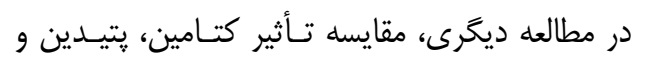

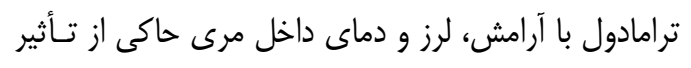

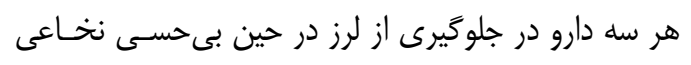

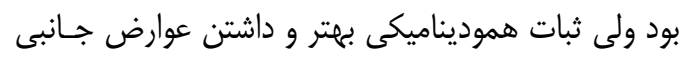

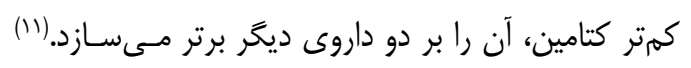

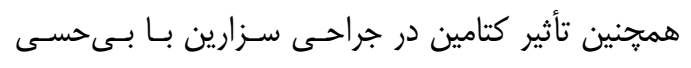


در اين مطالعه بلجز تزريق كتـامين سـاير متغيرهـاى

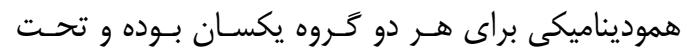

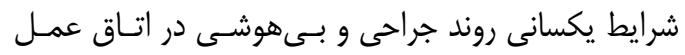

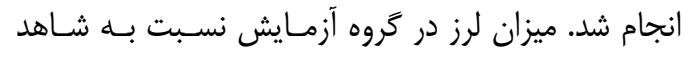

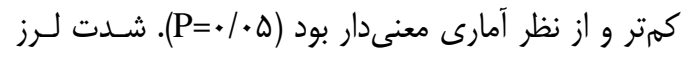

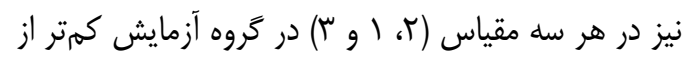

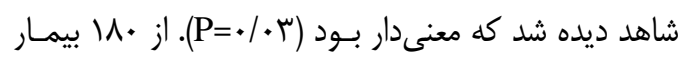

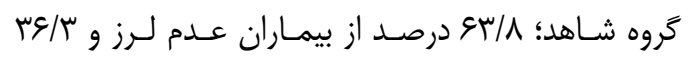

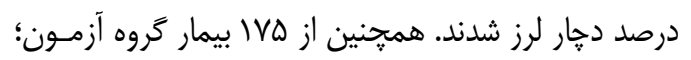

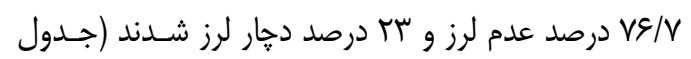
شماره r). در اين مطالعه ارتباط آمارى معنادارى بين كاهش لرز

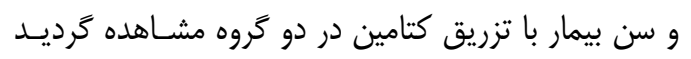

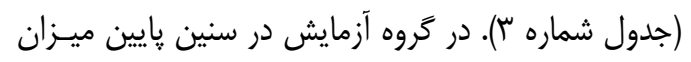

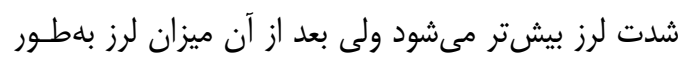

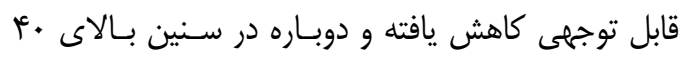

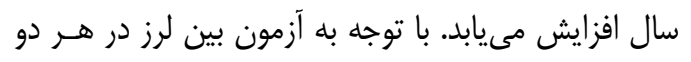

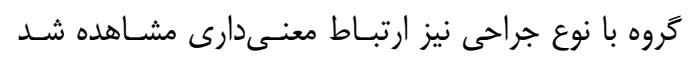

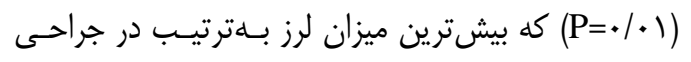

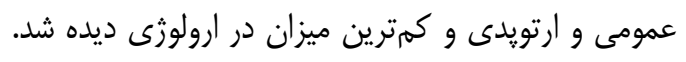

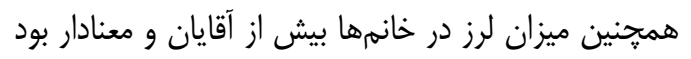

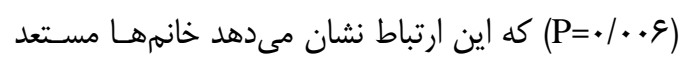

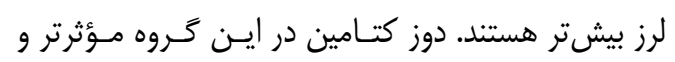
ضرورىتر مىباشد.

\section{جدول ا - طبقدبندى ميزان لرزش}

\begin{tabular}{|c|c|}
\hline علايم كلينيكى و بالينى لرز & درجه لرز \\
\hline بدون لرزش & · \\
\hline لرزش خفيف صورت و گردن & 1 \\
\hline لرزش قابل رؤيت در بيش از يك گروه عضله & r \\
\hline فعاليت شديد عضلانى كه تمام بدن را فرا كيرد & r \\
\hline
\end{tabular}

دارويى به مقدار / / • ميلىليتر بر كيلوكَرم دريافت كردند.

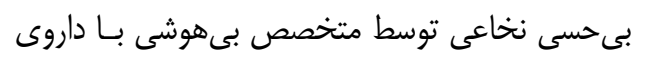

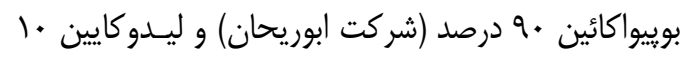

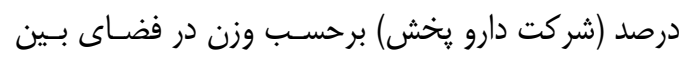

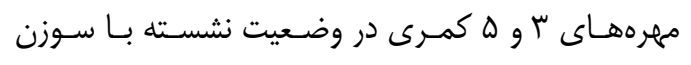

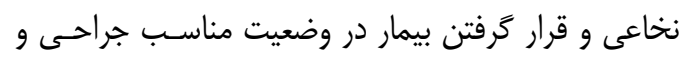

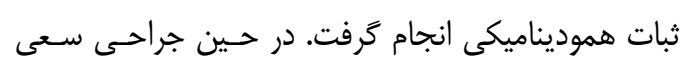

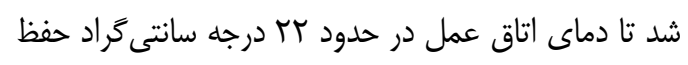

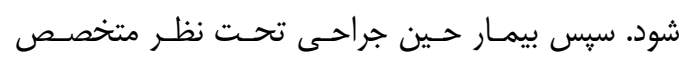

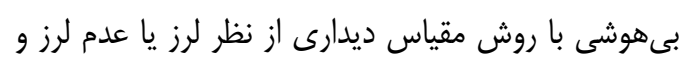
درجه لرزش (از درجه صفر تا سـه) مشـاهده و واطلاعـات

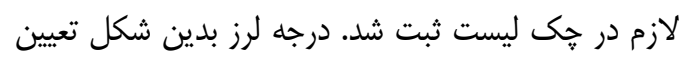

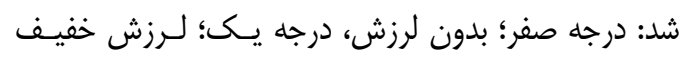

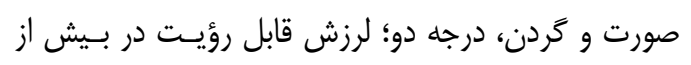

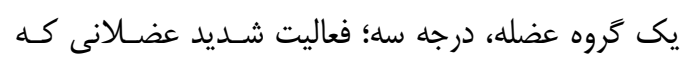

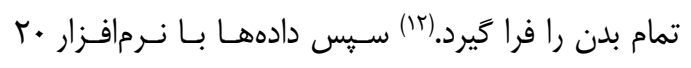
SPSS و آزمون تى مستقل و كاى اسكوئر تحليل شدند.

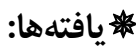

با توجه به توزيع طبيعى دادهها براى مقايسه دو گَروها: از آزمونهاى كاى دو و تى مستقل استفاده شد. ميـانخين

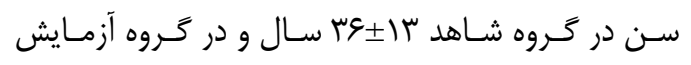

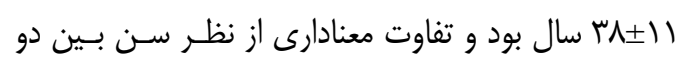

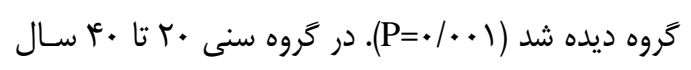

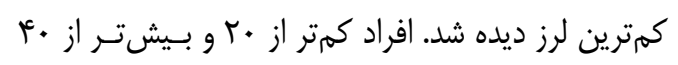

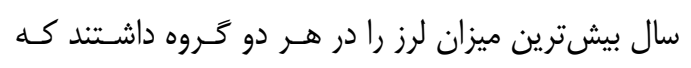

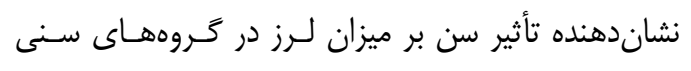

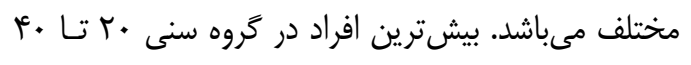

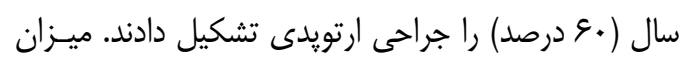

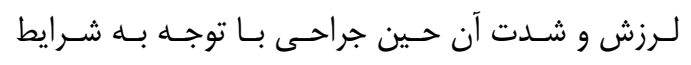

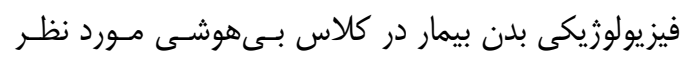

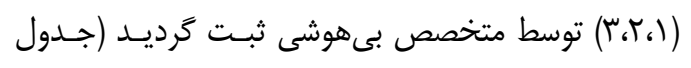

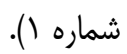




\section{جدول ؟ - تعيين ميزان درجه لرزش حين جراحى در كَروه آزمايش و شاهد با آزمون كاى اسكوئر}

\begin{tabular}{|c|c|c|c|c|c|c|c|}
\hline معنى دارى & جمع & سه & دو & يك & صفر & & \\
\hline \multirow[t]{6}{*}{.$/ 0$} & IVD & . & 1. & $r$. & Iro & تعداد بيمار & \multirow{2}{*}{ آزمايش } \\
\hline & $1 \ldots$ & . & 9 & IV & $V \& / V$ & درصد بيمار & \\
\hline & $1 \Lambda$. & $\mathrm{v}$ & 11 & f. & 110 & تعداد بيمار & \multirow{2}{*}{ شاهد } \\
\hline & $1 \ldots$ & f & 1. & $T r / \mu$ & $8 r / \Lambda$ & درصد بيمار & \\
\hline & $r \Delta \Delta$ & $\mathrm{v}$ & rq & v. & req & تعداد & \multirow{2}{*}{ كل } \\
\hline & $1 \ldots$ & $1 / 9$ & $N / 1$ & $19 / \mathrm{V}$ & v. & درصد & \\
\hline
\end{tabular}

جدول ب- تعيين ارتباط متغير هاى دموتر افيك با درجه لرزش در تروههاى مورد مطالعه با استفاده از آزمون كاى اسكوئر

\begin{tabular}{|c|c|c|c|c|c|c|c|}
\hline سطح معنى دارى & \multicolumn{2}{|c|}{ داراى لرزش (درجه ا تا ؟) } & \multicolumn{2}{|c|}{ عدم لرزش } & \multirow{2}{*}{ كروه } & \multirow{2}{*}{\multicolumn{2}{|c|}{ كروها متغير }} \\
\hline & مرصد & ت تعداد & درصد & تعداد & & & \\
\hline \multirow[t]{2}{*}{. } & I & זr & $F F / T$ & $\mathrm{VA}$ & 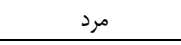 & \multirow{2}{*}{ جنسيت } & \multirow{9}{*}{ 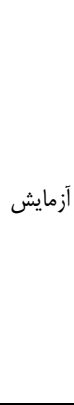 } \\
\hline & N/T & re & $r F / F$ & Tr & زن & & \\
\hline \multirow{3}{*}{$.1 \cdot 1$} & $1 F / V$ & re & $t V / \Lambda$ & 19 & عمومى & \multirow{3}{*}{ نوع جراحى } & \\
\hline & $1 . / r$ & $M$ & $\mathrm{r} / \mathrm{\Lambda}$ & $\Delta \varphi$ & ارتويدى & & \\
\hline & $r / \kappa$ & 9 & $11 / 9$ & ri & ارولوزى & & \\
\hline \multirow{4}{*}{.1 .4} & $r / 4$ & 8 & $V / r$ & זו & بيشتر يا مساوى ·· & \multirow{4}{*}{ 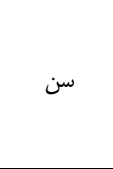 } & \\
\hline & $1 \pi / 9$ & $\mu^{f}$ & $K N / T^{\epsilon}$ & $\omega$. & r. r. & & \\
\hline & $V / F$ & זו & $T V / \Lambda$ & 19 & G. F. F. & & \\
\hline & $T / T$ & r & $9 / 9$ & IV & بيشتر يا مساوى .4 & & \\
\hline \multirow[t]{2}{*}{.$/ \cdot r$} & $1 F / \Delta$ & rq & $r \Delta / \bar{\beta}$ & is & مرد & \multirow{2}{*}{ جنسيت } & \multirow{5}{*}{ شاهد } \\
\hline & rø/द & is & rF & 91 & 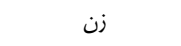 & & \\
\hline \multirow{3}{*}{$.1 \cdot 1$} & $r / r$ & rᄉ & ro/\& & is & 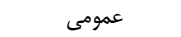 & \multirow{3}{*}{ نوع جراحى } & \\
\hline & $1 F / \Delta$ & re & ro & is & 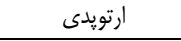 & & \\
\hline & $\Delta$ & 9 & $N / \kappa^{4}$ & 10 & 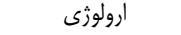 & & \\
\hline
\end{tabular}

مبحث و نتيجه كيرى

جراحى با بى حسى نخاعى تأثير بلهز ايى داشته و با كنترل

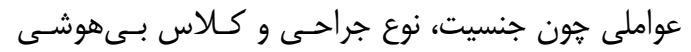

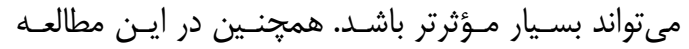

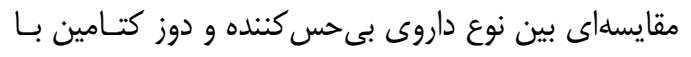

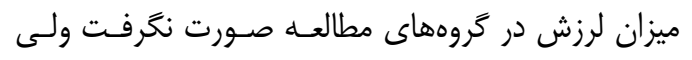
طبق مطالعات قبلى اين عامل هم مىتواند بسيار تأثير كذار

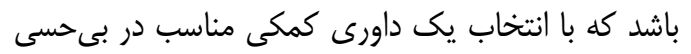

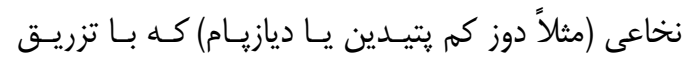

در اين مطالعه تزريق كتامين به ميزان كان / • ميلى

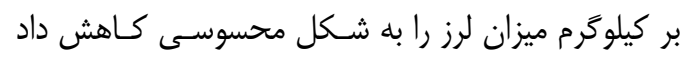

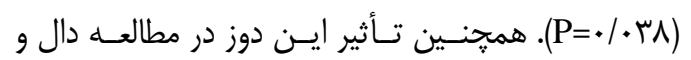

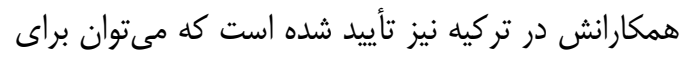

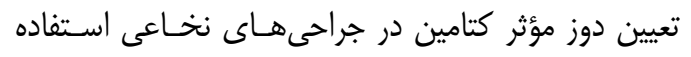

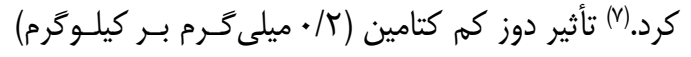
نسبت به استاندارد تعيين شده در ديكر مطالعـات (ه/ • تـا

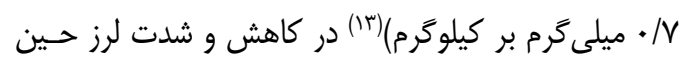




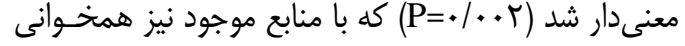

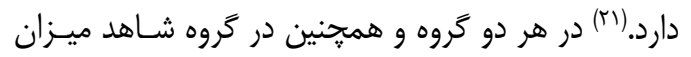

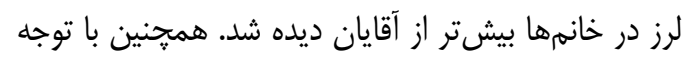

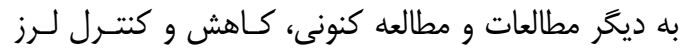

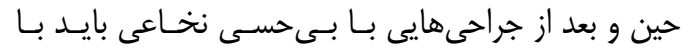

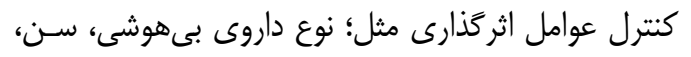

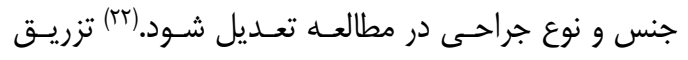

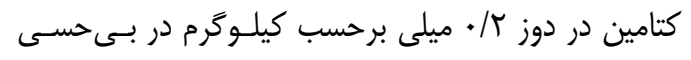

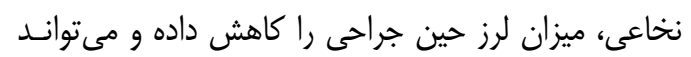

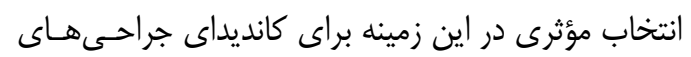

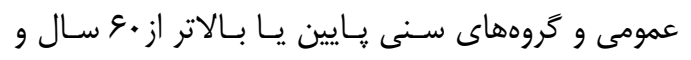

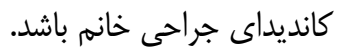

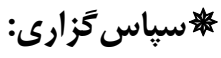

بدينوسيله از همكاران و كاركنان اتاق عمـل و كـادر

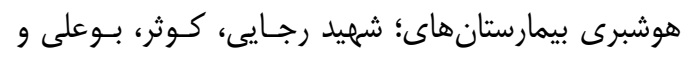

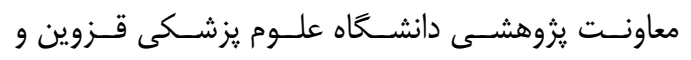

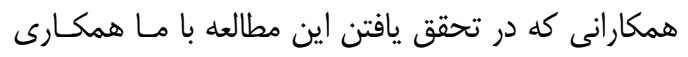

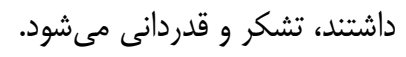

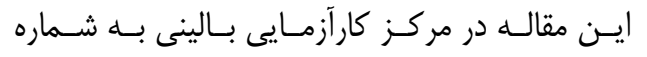

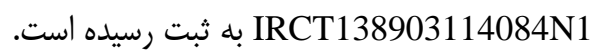

\section{مراجع:}

1. De White J, Sessler DI. Preoperative Shivering: physiology and pharmacology. Anesthesiology 2002; 96(2): 467-84

2. Bhatnagar S, Saxena A, Kannan TR, Punj J, Panigrahi M, Mishra S. Tramadol for post operative shiverin: a double-blind comparison with pethidine. Anesthesia Intensive Care 2001; 29(2): 149-54.

3. Katyal S, Tewari A. Shivering: Anesthesia considerations. J Anesthesiol Clin Pharmacol 2002; 18(4): 363-76.

4. Mathews S, Al Mulla A, Varghese PK, Radim K, Mumtaz S. Postanesthetic
كتامين تداخل هم افزايى يا كاهشى نداشته باشد مىتوان

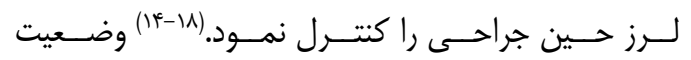

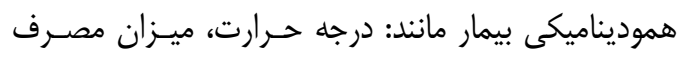

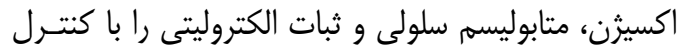

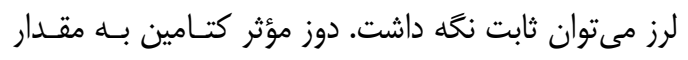

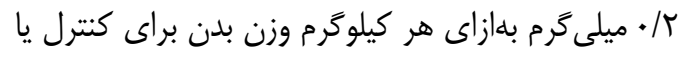

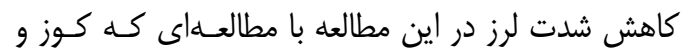

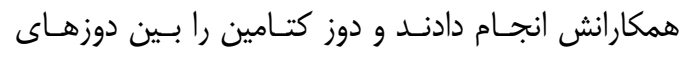

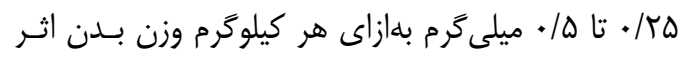

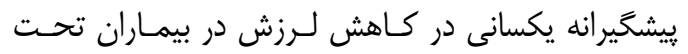

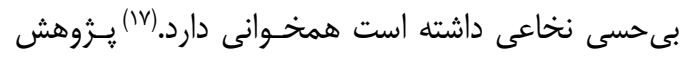

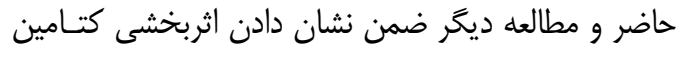
در كاهش لرز كه تأييدى بر نتيجه مطالعه حاضر مى وباشد، براى رسيدن به دوز واحد و مؤثر تأكيد دارد.(19) در اين مطالعه رابطه معنادارى بين سن و دوز كتامين

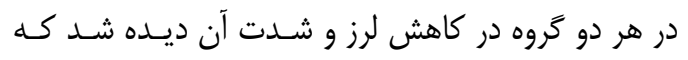

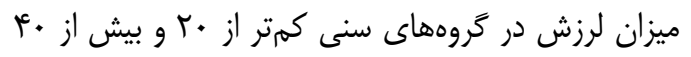

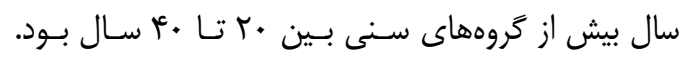

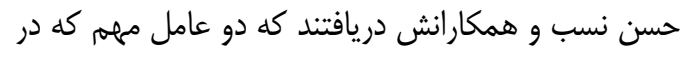

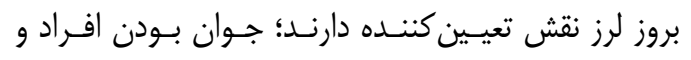
كاهش دماى مركزى بدن است. همجنين معتقدند كـهـ بــا

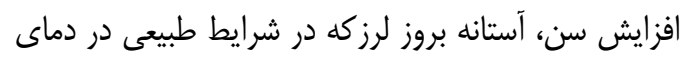
عب درجه سانتى كراد مىباشد در افراد مسـن ايـن آسـتانه

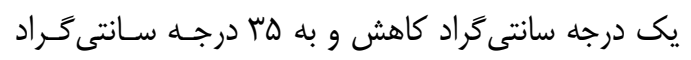

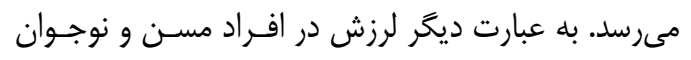

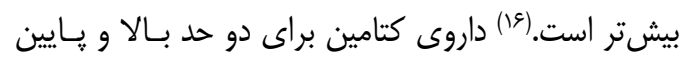

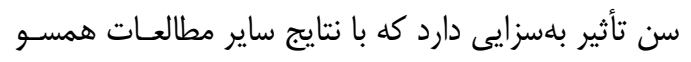

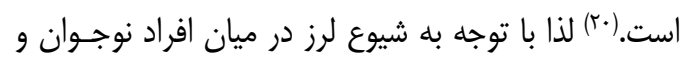

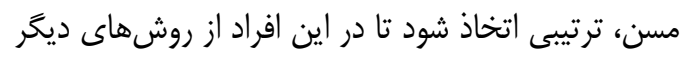
بى حسى يا بىهوشى اسـتفاده و يـا شـــايط لازم (تنظـيم

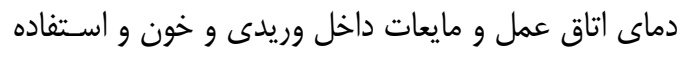

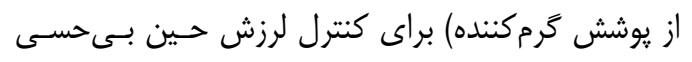
نخاعى براى بيمار - قبل از بى حسى - فراهم شود.

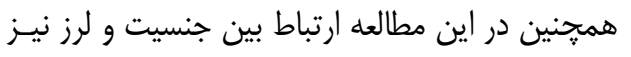


shivering - a new look at Tramadol. Anesthesia 2002; 57(4): 394-8.

5. Sagir O, Gulhas N, Topark H, Yucel A, Begec Z, Erosy O. Control of shivering during regional anesthesia: prophylactic Ketamine and Granisetron. Acta Anesthesiol Scand 2007; 51(1): 44-9. doi: 10.1111/j.13996576.2006.01196.x.

6. Misiran K, Aziz FZ. Effectiveness of lowdose Midazolam plus Ketamine in the prevention of shivering during spinal anesthesia for emergency lower limb surgery. South Afr J Anaesth Analg 2013; 19(3): 16470. doi: 10.1080/22201173.2013.10872917.

7. Dal D, Kose A, Honca M, Akinci SB, Basgul E, Aypar U. Efficacy of prophylactic Ketamine in preventing postoperative shivering. Br J Anaesth 2005; 95(2): 189-92. doi: 10.1093/bja/aei148.

8. Cattaneo CG, Frank SM, Hesel TW, ElRahmany HK, Kim LJ, Tran KM. The accuracy and precision of body temperature monitoring methodsduring regional and general anesthesia. Anesth Analg 2000; 90(4): 938-45. doi: 10.1213/00000539200004000-00030.

9. Tsai YC, Chu KS. A comparison of tramadol, amitriptyline, and meperidine for postepidural anesthetic shivering in parturients. Anesth Analg 2001; 93(5): 128892. doi: 10.1097/00000539-20011100000052.

10. Gangopadhyay S, Gupta K, Acharjee S, Nayak SK, Dawn S, Piplai G. Ketamine, Tramadol and Pethidine in prophylaxis of shivering during spinal anesthesia. J Anaesth Clin Pharmacol 2010; 26(1): 59-63.

11. Kose EA, Honca M, Dal D, Akinic SB, Aypar U. Prophylactic Ketamine to prevent shivering in parturients undergoing cesarean delivery during spinal anesthesia. J Clin
Anesth 2013; 25(4): 275-80. doi: 10.1016/j. jclinane.2012.11.014.

12. Pazoki SH, Norouzi A, Shademan AH. Comparison effect of different doses of Ketamine with Pethedine in reducing postoperative shivering after cesarean section. Arak Med Univ J 2009; 12(2): 9-16 [In Persian]

13. Mahoori AR, Valizade Hasanloei MA, Hassani E, Sadighi F. The effect of intravenous low dose ketamine for prevention of shivering after inguinal herniorrhaohy. Urmia Med J 2013; 24(10): 779-84. [In Persian]

14. Sellden E, Lindahl SG. Amino acidinduced thermogenesis reduces hypothermia during anaesthesia and shortens hospital stay. Anesth Analg 1999; 89(6): 1551-6. doi: 10. 1213/00000539-199912000-00045.

15. Kelsaka E, Baris S, Karakaya D, Sarihasan B. Comparison of Ondansetron and Meperidine for prevention of shiveringin patients undergoing spinal anesthesia. Reg Anesth Pain Med 2006; 31(1): 40-45.

16. Hasannasab B, Banihasham N, Khoshbakht A, ShirKhani Z. Efficacy of prophylactic low dose ketamine in preventing shivering after general anesthesia . J Mazandran Univ Med Sci J 2013; 23(103): 89-93. [In Persian]

17. Kose EA, Dal D, Akincis SB, Saricaoglu F, Aypar U. The efficacy of Ketamine for treatment of postoperative shivering. Anesth Analg 2008; 106(1): 120-2. doi: 10.1213/01. ane.0000296458.16313.7c.

18. Bock M, Motsch J. Postanesthetic shivering. Hospital Pharmacy. https://link.springer.com/chapter/10.1007/978 -4-431-67035-3_17by M Bock - 2001. 42(2). 2007; 424-29. https://doi.org/10.1007/978-4431-67035-3_17. 
19. Ahmed A, Aslam M. Prevention of shivering during lower segment cesarean section; Comparison of prophylactic use of ketamine, and ketamine plus midazolam during spinal anesthesia. Professional Med J 2013; 20(3); 409-15.

20. Yousuf B, Samad K, Ullah H, Hoda MQ. Efficacy of tramadol in preventing postoperative shivering using thiopentone or Propofol as induction agent: A randomized contolled trial. J Anesthesiol Clin Pharmacol 2013; 29(4): 521-5. doi: 10.4103/0970-9185. 119166.
21. Nakasuji M1, Nakamura M, Imanaka N, Tanaka M, Nomura M, Suh SH. Intraoperative small dose of ketamine prevents Remifentanil-induced post anesthesia shivering. Anesth Analg 2011; 113(3): 484-7. doi: 10.1213/ANE. 0b013e318224ac4e.

22. Koeshardiandi M, Margarita N. The effectiveness of ketamine dose $0.25 \mathrm{mg} / \mathrm{kg}$ body weight intravenous as a therapy of shivering during spinal anesthesia in section caesaria surgery. Media J Emergency 2011. 1(1): 12. 